\title{
Percepção dos trabalhadores de enfermagem acerca da satisfação no contexto do trabalho na UTI
}

Recebido em: 28/10/2011

Aceito em: 16/04/2012

\author{
Rosemary Silva da Silveira ${ }^{1}$ \\ Cíntia Regina Funck ${ }^{2}$ \\ Valéria Lerch Lunardi ${ }^{3}$ \\ Juliana Teixeira da Silveira ${ }^{4}$ \\ Liziani Iturriet Avila ${ }^{5}$ \\ Wilson Danilo Lunardi Filho ${ }^{6}$ \\ Danielle Adriane Silveira Vidal ${ }^{7}$
}

\begin{abstract}
Objetivou-se conhecer as percepções dos trabalhadores de enfermagem acerca da satisfação ou ausência de satisfação no contexto do trabalho de uma Unidade de Terapia Intensiva. Realizou-se a pesquisa qualitativa por meio da técnica de entrevista com 13 trabalhadores. Do processo de análise, emergiram duas categorias: o trabalho como fonte de satisfação para os trabalhadores da enfermagem da UTI e a ausência de satisfação no contexto do fazer dos trabalhadores da enfermagem da UTI.
\end{abstract}

Descritores: Trabalhadores, Enfermagem, Satisfação no Trabalho.

\section{Perception of nursing staff about the satisfaction in work in the ICU}

It was aimed to find out about the perceptions of the Nursing workers regarding the satisfaction or lack of satisfaction in the context of the job in the Intensive Care Unit. A qualitative survey was carried out by means of interviews with thirteen workers. From the process of the analysis, two categories emerged: Working as a source of satisfaction for the nursing workers in the ICU and Lack of satisfaction in the context of the job of the workers in the ICU.

Descriptors: Workers, Nursing, Satisfaction at Work.

\section{Percepción del personal de enfermería acerca de la satisfacción en el trabajo en la UCI}

Se objetivó conocer la percepción de los trabajadores de enfermería acerca de la satisfacción o falta de satisfacción en el contexto de trabajo en una Unidad de Terapia Intensiva. Se ha realizado la pesquisa cualitativa de encuesta con trece trabajadores. Del proceso de análisis, emergieron dos categorías: el trabajo como medio de satisfacción para los trabajadores de enfermería de la UTI y la falta de satisfacción en el contexto del hacer de los trabajadores de enfermería de la UTI.

Descriptores: Trabajadores, Enfermería, Satisfacción en el Trabajo.

\section{INTRODUÇÃO}

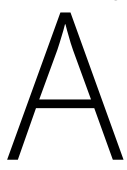

satisfação no trabalho exerce influência positiva sobre o trabalhador e pode se manifestar com melhorias em sua saúde, qualidade de vida e comportamento, trazendo benefícios para os indivíduos e para as organizações ${ }^{(1)}$. A ausência de boas condições no contexto do trabalho pode produzir insatisfação nos trabalhadores da enfermagem, com possíveis prejuízos em seu viver.

Aodesenvolver as atividades práticas no Hospital Universitário (HU), tem-se percebido uma "aparente" insatisfação no contexto do trabalho da enfermagem, evidenciada por situações que influenciam negativamente a construção do trabalho da enfermagem como um processo coletivo(2).

Ao buscar compreender o porquê dessa insatisfação manifestada por alguns trabalhadores de enfermagem, tem-se questionado sobre suas condições de trabalhoe sobre a aparente submissão e falta de exercício da autonomia dos trabalhadores, perguntando-se: como favorecer o enfrentamento dos conflitos de modo a produzir maior satisfação no contexto de trabalho da enfermagem? Como o trabalhador pode sentirse satisfeito e realizado e ser capaz de exercer sua autonomia e tomar decisões? A obtenção de satisfação no/do trabalho pode favorecer o comprometimento e a consciência individual e coletiva dos trabalhadores de enfermagem? O que produz

1 Enfermeira. Professora da Escola de Enfermagem e do Programa de Pós-Graduação em Enfermagem (PPGEnf) da Universidade Federal do Rio Grande (Furg). Doutora em enfermagem. Membro do Núcleo de Estudos e Pesquisa em Enfermagem e Saúde (Nepes) e do Giate. E-mail: anacarol@mikrus.com.br.

2 Enfermeira. Membro do Nepes/Furg.

3 Enfermeira. Professora do Programa de Pós-Graduação em Enfermagem da Furg - membro do Nepes. Doutora em enfermagem. Pesquisadora do CNPq.

4 Enfermeira. Mestranda do PPGEnf. Membro do Nepes/Furg

5 Enfermeira. Mestranda do PPGEnf. Membro do Nepes/Furg. Bolsista da Capes.

6 Enfermeiro. Professor da Escola de Enfermagem e do Programa de Pós-Graduação da Furg. Membro do Nepes. Doutor em enfermagem da UFSC.

7 Enfermeira. Mestranda do PPGEnf. Membro do Nepes/Furg. Bolsista do CNPq. 
satisfação e ausência de satisfação no fazer dos trabalhadores da enfermagem?

Objetivou-se conhecer as percepções dos trabalhadores da enfermagem acerca da satisfação ou insatisfação no contexto do trabalho da Unidade de Terapia Intensiva (UTI).

\section{METODOLOGIA}

Trata-se de uma pesquisa qualitativa, exploratória(3), desenvolvida em uma Unidade de Terapia Intensiva (UTI) de um Hospital Universitário (HU) do extremo sul do Brasil, que atende usuários do Sistema Único de Saúde, com idade superior a 12 anos; dispõe de seis leitos, dos quais um é de isolamento.

De um total de 23 trabalhadores de enfermagem que atuam na UTI, 13 aceitaram e foram participantes desse estudo. Após sua assinatura do Termo de Consentimento Livre e Esclarecido, entre abril e junho de 2010, realizaram-se entrevistas, com questões abertas, numa tentativa de elucidar as percepções dos trabalhadores da enfermagem acerca da satisfação ou insatisfação no contexto de trabalho da UTI. Para preservar o anonimato dos entrevistados, seus nomes foram representados pela letra $T$, seguida de números.

Os dados foram submetidos a análise na busca de seu real e profundo significado "para proporcionar uma explicação dos eventos, como ocorrem na realidade não como foram contextualizados nas teorias pré-existentes"(3:148), construindose duas categorias.

Obteve-se a aprovação do Comitê de Ética em Pesquisa na Área da Saúde - Cepas/ Furg, parecer n 131/2009.

\section{RESULTADOS}

O trabalho como fonte de satisfação para os trabalhadores da enfermagem da UTI

Os trabalhadores associaram a satisfação no trabalho por possibilitar atender a suas necessidades de sobrevivência:

É desempenhar minhas funções visando à remuneração [...] produzo, exerço uma produção e recebo em função disso. (T3)

A manutenção da vida porque a gente precisa do dinheiro para sobreviver. (T5)

A satisfação no trabalho parece decorrer da identificação do trabalhador com a atividade desempenhada:

Trabalho é uma atividade que a gente escolhe a partir de uma determinada sintonia, de alguma coisa que te dê satisfação [...] que te dê prazer de fazer aquela atividade. (T5)

É uma atividade que a gente escolhe por afinidade, o teu perfil para determinada profissão [...] uma coisa que te dê uma satisfação pessoal. (T10)

A satisfação dos trabalhadores está atrelada à possibilidade de efetivar suas atividades, bem como compreender que situações desgastantes, no contexto da UTI, não podem caracterizar o trabalho como produtor de ausência de satisfação:
Eu me considero satisfeito, apesar de entender que há muitas coisas que a gente não consegue e não vai conseguir resolver, que há muitas situações que estão além da nossa própria gerência.(T1)

A satisfação no trabalho parece articulada à constatação do trabalhador da contribuição de seu fazer para a recuperação e melhoria dos pacientes na UTI:

A satisfação é saber que eu estou sendo útil, saber que eu estou ali e tem gente precisando de $\mathrm{mim}$. (T9)

Quando a gente consegue ter um paciente que tenha condições de se recuperar, revê-lo depois com condições de manter uma vida ativa, essa é a nossa grande satisfação.(T10)

O trabalho desenvolvido em equipe parece fortalecer o sentimento de satisfação no trabalho:

É saber que eu tenho o apoio dos meus colegas, que eu estou trabalhando com uma equipe boa. Isso te traz satisfação assim por trabalhar num ambiente bom.(T4)

A ausência de satisfação no contexto do fazer dos trabalhadores da enfermagem da UTI

Trabalhar em uma UTI, por se constituir em um ambiente fechado, com a permanência dos trabalhadores nesse ambiente, em contato muito próximo dos pacientes em estado grave, parece constituir-se em fonte de insatisfação para o trabalhador:

O ambiente fechado da UTI, a questão de não ter contato com o sol, com a brisa, com

o ambiente externo, é um pouco angustiante, é algo negativo para o ambiente de trabalho. (T1)

Pesado, estressante, a própria condição dos pacientes aqui na UTI, trabalhar em ambiente fechado, estar sempre junto do paciente [...] até na copa estou enxergando os pacientes. (T8)

A ausência de satisfação dos trabalhadores pode estar relacionada às condições clínicas apresentadas pelos pacientes e à possível dificuldade dos trabalhadores em realizar ações de cuidado diante de um prognóstico desfavorável:

Não dá satisfação de fazer o cuidado, algo que você imagina e percebe que não vai ser efetivo, talvez pela condição do paciente, pela história da doença ou por condição irreversível. (T1)

As condições inadequadas de trabalho com precariedade e insuficiência de recursos materiais são justificativas apresentadas pelos trabalhadores para mostrarem-se insatisfeitos com sua atividade laboral:

Falta de materiais básicos causa estresse, transtorno, demora para conseguir realizar o procedimento. (T6)

A gente vive em função do que tem [...] teve um tempão sem soro de 125 e $250 \mathrm{ml}$ [...] a gente desperdiça muito material tendo que colocar fora, perde muito tempo desprezando.(T3)

A organização inadequada do trabalho no que se refere às atribuições a serem desempenhadas também contribui para a falta de satisfação dos trabalhadores: 
Atender o telefone, a campainha, o interfone; ter que fazer coisas extras [...] porque a gente deixa de prestar um cuidado melhor ou maior para o paciente. (T3)

A desunião da equipe, associada à falta de comprometimento de alguns trabalhadores e da não-valorização do trabalho realizado, favorece a insatisfação dos entrevistados, provocando-lhes sofrimento:

Ausência de satisfação é quando a equipe não é unida num objetivo só [...] tu percebe que não tem colaboração, não tem ajuda da equipe.(T4)

[...] tu faz e às vezes não é reconhecido por aquilo que faz." (T7)

Uma coisa que me deixa um pouco insatisfeito é quando começam a aparecer coisas erradas com os pacientes, por exemplo, um paciente que apresenta uma escara, porque deveria ter sido mudado de decúbito mais vezes e não foi. (T8)

\section{DISCUSSÃO}

A percepção dos trabalhadores acerca da satisfação ou insatisfação no contexto do trabalho da Unidade de Terapia Intensiva (UTI) relaciona-se, inicialmente, com a satisfação das próprias necessidades, uma forma de garantir sua sobrevivência e o sustento de sua família. Ou seja, "além das necessidades relacionadas à reprodução e à sobrevivência do corpo biológico, esse ser humano, por se constituir um ser social, precisa atender a uma série de necessidades para viver"(4:221).

O trabalho desenvolvido na UTI possibilita ao trabalhador ampliar a compreensão sobre a importância de seu fazer e, também, a descoberta da razão pela qual escolheu fazer parte de uma profissão que tem como fim de seu trabalho o cuidado da vida dos seres humanos. Mesmo que exaustivo, cansativo, a clareza em relação à finalidade do trabalho na UTI requer responsabilidade, compromisso e envolvimento com o paciente, conferindo significado a sua existência ${ }^{(5)}$.

Apesardoestresseconstanteedaagilidadepermanentemente exigida nesse tipo de ambiente, os trabalhadores referem que, ao mesmo tempo em que desenvolvem um trabalho exaustivo, ele é gratificante. A gratificação e a valorização obtidas através do trabalho na UTI podem influenciar a conduta do trabalhador, estimulando-o à satisfação. A satisfação pode ser percebida "como um dos principais fatores relacionados com a produtividade e a qualidade do trabalho". Pode, ainda, possibilitar que o trabalhador se torne mais responsável, favorecendo seu reconhecimento e a realização pessoal e profissional $^{(6: 34)}$.

Quando o trabalhador visualiza a qualidade de seu fazer ao rever um paciente com "vida ativa", demonstra que sua satisfação decorre da relação estabelecida com o outro, do comprometimento com a vida e, ainda, do vínculo entre quem cuida e quem é cuidado ao efetivar as ações de cuidado. Nessas ações "estão implícitas as relações humanas e as implicações que definem sua prática e tudo a sua volta"(7:567).
A satisfação obtida através do apoio dos colegas pode ser proporcionada pelo clima de tranquilidade, confiança, harmonia, amizade e respeito, estabelecido entre os trabalhadores e, ainda, com o usuário e seus familiares, sendo importantes não somente como valores, mas como possibilidade de desenvolver habilidades de relacionamentos e favorecer o trabalho em equipe ${ }^{(2)}$.

O trabalho desenvolvido na UTI tem uma especificidade própria, por ser um setor fechado, restrito, com uma complexidade de recursos e cuidados dispensados aos pacientes, bem como por submeter os trabalhadores a uma constante necessidade de estado de alerta, tendo em vista o desequilíbrio hemodinâmico dos pacientes e o risco de possíveis complicações e de morte ${ }^{(8)}$. São características que podem contribuir para o desenvolvimento de sentimentos de ansiedade, angústia e sofrimento, além de ausência de satisfação com o desempenho do trabalho nesse ambiente.

Uma das condições que provocam ausência de satisfação e sofrimento refere-se à dificuldade do trabalhador por se deparar com situações em que o usuários apresentam mau prognóstico ou se encontram em fase terminal. Cabe destacar que a promoção de ações de cuidado pode estar sendo compreendida como desnecessária, como a possibilidade de prolongar a vida sem qualidade, dificultando que o trabalhador enfrente o processo de morte e o morrer ${ }^{(9)}$.

Além de fatores como a constante observação, a necessidade de atenção para as mudanças no quadro clínico dos pacientes, a estrutura física e a ausência de compromisso com o cuidado podem ocasionar estresse nesses trabalhadores, influenciando seu estado de satisfação( ${ }^{(5)}$.

Um dos fatores que influenciam negativamente a motivação e produzem ausência de satisfação no trabalho é a improvisação e a falta de recursos materiais, pois trabalhar com escassez de recursos impossibilita o trabalhador de realizar uma assistência de qualidade. Ou seja, a ausência de infraestrutura adequada compromete o processo de cuidar ${ }^{(10)}$, especialmente em uma unidade de cuidados complexos a pacientes graves e com risco de vida, como em uma UTI.

Assim, a ausência de satisfação e a presença de desgaste no trabalho também estão relacionadas ao tempo improdutivo dispensado para assumir outros papéis imprescindíveis para possibilitar que o trabalho da enfermagem seja implementado. A organização do trabalho da enfermagem "tem sido penalizada com a deficiência dos recursos humanos e materiais, o que interfere diretamente na qualidade da assistência prestada à população, gerando insatisfação nos profissionais que se sentem impotentes e frustrados com a situação"(10:157).

A ausência de satisfação no contexto de trabalho pode ser ocasionada pela falta de reconhecimento e desunião entre os demais membros da equipe de saúde. A desunião entre os 
trabalhadores da UTI pode afetar suas relações interpessoais, pois é a partir da interação com o outro que são estabelecidos os vínculos profissionais. Assim, o cotidiano de trabalho pode ser influenciado por relações desfavoráveis, tensas, que dificultam o desenvolvimento e a realização das ações dos trabalhadores de modo coletivo ${ }^{(11)}$.

A ausência de realização de ações básicas de cuidado com os pacientes e a dificuldade para visualizar o trabalho da enfermagem de modo contínuo podem provocar ausência de satisfação do trabalhador, tanto por deparar-se com problemas que precisariam ser priorizados, mas nem sempre são solucionados, quanto pelas implicações decorrentes da ausência do comprometimento com o cuidado. O descompromisso de alguns trabalhadores da saúde da UTI pode "tornar a assistência restrita a um fazer técnico, ou seja, descaracterizar o cuidado como ação humana, ou mesmo nem o fazer técnico ser realizado adequadamente"(2:153).

Estar atento à necessidade de cuidar, observando "a posição do usuário no leito, as áreas de hiperemias, à necessidade de mudar seu decúbito ou de realizar a higiene oral e corporal nunca são meramente observações de fatos - são observações éticas", que envolvem o conhecimento como um valor inseparável do respeito ao outro em sua integralidade, como uma expressão de envolvimento essencial para a realização pessoal e profissional do trabalhador (2:117).

Apesar de algumas dificuldades relacionadas às relações interpessoais, acredita-se ser possível favorecer a interação, possibilitando que cada trabalhador possa comprometerse consigo mesmo e com as atribuições e competências individuais; requerendo um olhar, tanto para si mesmos, quanto para a realidade em que estão inseridos; pautando suas ações em princípios e valores, reconhecendo o dever de respeitar e o direito de ser respeitado ${ }^{(12)}$.
Quando o trabalhador desenvolve seu trabalho com prazer, com compromisso, sendo valorizado através de um julgamento positivo em relação a seu fazer, o ambiente de trabalho poderá ser compreendido como um local de reconhecimento e crescimento pessoal e, ainda, de realizações e de valorização do trabalhador. O reconhecimento e o prestígio social podem, ainda, fazer com que o trabalhador se sinta satisfeito com as atividades desempenhadas no contexto de trabalho da UTI e perante a sociedade.

\section{CONCLUSÕES}

Foi possível constatar a percepção dos trabalhadores de que a satisfação no processo de trabalho parece favorecer seu desempenho profissional. E, apesar de os trabalhadores da enfermagem constituírem o maior contingente da força de trabalho na área da saúde, ainda são inúmeras as dificuldades para melhorar suas condições de trabalho, as quais produzem a ausência de satisfação. A existência de um ambiente harmônico pode influenciar os trabalhadores a organizar o contexto de trabalho na busca de objetivos comuns, favorecendo o trabalho em equipe, o respeito pelo fazer do outro, os laços de confiança e de amizade, alcançando resultados coletivos satisfatórios.

Uma vez que cada trabalhador da enfermagem direcionar um olhar para o que lhe satisfaz ou produz ausência de satisfação no contexto de trabalho, poderá compreender a importância de seu fazer e da função de cada membro da equipe de enfermagem como funções especializadas que se complementam para a consecução do processo de produção, obtendo, assim, maior satisfação.

O conhecimento produzido com esta pesquisa poderá chamar a atenção dos trabalhadores frente às situações inadequadas de trabalho, podendo suscitar discussões e reflexões sobre as condições do trabalho no ambiente da UTI.

\section{Referências}

1. Martinez CM, Paraguay AIBB. Satisfação e saúde no trabalho - aspectos

conceituais e metodológicos [Internet]. [citado em 2012 Fev 20]. Disponível em:

http://www.usp.br/ip

2. Silveira RS. A construção moral do trabalhador de saúde como sujeito autônomo

e ético [tese]. Florianópolis: Universidade Federal de Santa Catarina; 2006.

3. Polit D, Beck CT. Fundamentos de pesquisa em enfermagem. 7a ed. Porto

Alegre: Artmed; 2011.

4. Sanna MC. Os processos de trabalho em enfermagem. Rev Bras Enferm.

2007;60(2):221-8.

5. Cecere DBB, Silveira SS, Duarte CR, Fernandes GFM. Compromisso ético no trabalho da enfermagem no cenário da internação hospitalar. Enferm Foco. 2010;1(2):46-50.

6. Bezerra FD, Andrade MFC, Andrade JS, Vieira MJ, Pimentel D. Motivação da equipe e estratégias motivacionais adotadas pelo enfermeiro. Rev Bras Enferm. 2010;63(1):33-7.
7. Regis LFLV, Porto IS. A equipe de enfermagem e Maslow: (in)satisfaçōes no

trabalho. Rev Bras Enferm. 2006;59(4):565-8.

8. Silveira RS, Lunardi VL, Lunardi Filho WD, Oliveira AMN. Uma tentativa de

humanizar a relação da equipe de enfermagem com a família de pacientes

internados na UTI. Texto Contexto Enferm. 2005;14(Esp.):125-30.

9. Carvalho KK, Lunardi VL. Obstinação terapêutica como questão ética:

enfermeiras de unidades de terapia intensiva [Internet]. [citado em 2012 Jan 29].

Disponível em: http://www.scielo.br/pdf/rlae/v17n3/pt_05.pdf

10. Spindola T, Santos RS. O trabalho na enfermagem e seu significado para as

profissionais. Rev Bras Enferm. 2005;58(2):156-60.

11. Wagner LR, Thofehrn MB, Amestoy SC, Porto AR, Arrieira ICO. Relações

interpessoais no trabalho: percepção de técnicos e auxiliares de enfermagem.

Cogitare Enferm. 2009;14(1):107-13.

12. Oguisso T, Zoboli E. Ética e bioética: desafios para a enfermagem e a saúde. Barueri: Manole; 2006. 